\title{
The level of urinary IL-18 in acute kidney injury after cardiopulmonary bypass
}

\author{
CHANGAN WANG, JINGHUA ZHANG, JIANLE HAN, QINGYAN YANG, JINRUI LIU and BING LIANG \\ Renal Transplant Division, Department of Nephrology, Zhengzhou No. 7 People's Hospital, \\ Zhengzhou, Henan 450017, P.R. China
}

Received August 16, 2017; Accepted October 5, 2017

DOI: $10.3892 /$ etm.2017.5317

\begin{abstract}
This study investigated the diagnostic value of urinary interleukin-18 (uIL-18) in acute kidney injury (AKI) after cardiopulmonary bypass (CPB) in clinical practice. A total of 103 patients who underwent CPB were divided into the AKI group and non-AKI group according to the diagnostic criteria of AKI, and we collected the urine samples before and at 2, 4, 6, 8 and $12 \mathrm{~h}$ after CPB and the blood samples before and at 12, 24, 48 and $72 \mathrm{~h}$ after CPB for detection of the levels of uIL-18 and urinary neutrophil gelatinase-associated lipocalin (uNGAL) in urine samples and the levels of serum creatinine (Scr) in blood samples, respectively. With the results of detection, we measured the sensitivity and specificity of uIL-18 and uNGAL levels at $2 \mathrm{~h}$ after CPB in early diagnosis of AKI using the receiver operating characteristic (ROC) curve and area under curve (AUC). There were a total of 22 patients $(21.4 \%)$ with AKI. From $12 \mathrm{~h}$ after CPB, the level of Scr in the AKI group was significantly elevated, and this increasing trend lasted for $60 \mathrm{~h}$; comparisons with the levels before CPB and in non-AKI group showed that the differences had statistical significance $(\mathrm{P}<0.05)$. In AKI group, uIL-18 attained the peak level at $2 \mathrm{~h}$ after CPB, and the high level lasted for $10 \mathrm{~h}$; comparisons with the levels before CPB and in non-AKI group showed that the differences had statistical significance $(\mathrm{P}<0.05) ; 2 \mathrm{~h}$ after $\mathrm{CPB}$, the AUC was 90.48, and when the critical value was set as $1.6 \mu \mathrm{g} / 1$, the sensitivity and specificity was 90.91 and $91.36 \%$, respectively. Although there was a significant elevation in UNGAL level at $2 \mathrm{~h}$ after CPB in the AKI group, the level was dramatically decreased as soon as the peak level was attained at $4 \mathrm{~h}$, and the high level only lasted for $8 \mathrm{~h}$; difference between the level at $2 \mathrm{~h}$ after CPB and the level before $\mathrm{CPB}$ as well as that in the non-AKI group had statistical significance $(\mathrm{P}<0.05)$; at $2 \mathrm{~h}$ after $\mathrm{CPB}$, the AUC was 83.25 , and when the critical value was set as $100 \mu \mathrm{g} / 1$, the
\end{abstract}

Correspondence to: Dr Jinghua Zhang, Renal Transplant Division, Department of Nephrology, Zhengzhou No. 7 People's Hospital, 17 Jingnanwu Road, Zhengzhou, Henan 450017, P.R. China

E-mail: drjinghuazhang@163.com

Key words: urinary interleukin-18, acute kidney injury, neutrophil gelatinase-associated lipocalin, cardiopulmonary bypass sensitivity and specificity was, respectively 90.91 and $93.83 \%$. The results indicated that after CPB, the level of uIL-18 shows a more promising diagnostic value in clinical practice than $\mathrm{Scr}$ and UNGAL in early diagnosis of AKI.

\section{Introduction}

Acute kidney injury (AKI) has been identified as an independent risk factor for significant increase in incidence rate and the mortality rate after cardiopulmonary bypass (CPB) with a complicated pathogenesis, and also a common complication after CPB (1). Serum creatinine and urinary volume, as common and non-specific indicators in diagnosis and staging criteria of AKI, have shown poor sensitivity and are susceptible to the external factors, thereby decreasing their capabilities in precise reflection of the slight variations in renal function and delaying the accurate diagnosis of AKI in clinical practice (2). Clinically, there remain no effective indicators for early prediction and diagnosis of AKI, thereby resulting in a particularly high incidence rate and mortality rate of AKI after CPB due to delayed efficient treatment methods. Thus, screening out the indicators for early diagnosis of AKI can significantly ameliorate the prognosis of AKI patients through efficient treatment methods in advance and decrease in mortality rate (3). Study has shown that urinary interleukin-8 (uIL-8) and urinary neutrophil gelatinase-associated lipocalin (uNGAL) have promising sensitivity in early diagnosis of AKI after CPB (4-8). In this study, we aimed to investigate the application value of uIL-18 and UNGAL in urine samples in early diagnosis of AKI after CPB through detecting the dynamic changes in levels of uIL-18 and uNGAL collected from the clinical data of patients.

\section{Materials and methods}

Subjects. A total of 103 patients who underwent CPB between March and October, 2014 were enrolled as subjects. The criteria for enrollment of subjects: i) patients without renal and hepatic dysfunction, tumors, or medication history of nephrotoxic drugs before $\mathrm{CPB}$; ii) patients without unstable vital signs before $\mathrm{CPB}$; iii) patients conforming to the diagnostic criteria of AKI, i.e. the Scr level was $>26.5 \mu \mathrm{M}$, or exceeded $50 \%$ of the baseline level of Scr (9). This study was approved by the 
Table I. Comparisons of Scr levels at different time-points in the non-AKI group and the AKI group (Umol/1, mean $\pm \mathrm{SD})$.

\begin{tabular}{lccccrr}
\hline Time-point & Non-AKI group & AKI group & P-value & t-test & P-value & F-value \\
\hline Before CPB & $62.34 \pm 11.37$ & $65.22 \pm 10.46$ & 0.2868 & 1.071 & & \\
At 2 h after CPB & $63.11 \pm 13.89$ & $67.78 \pm 13.55$ & 0.1629 & 1.406 & 0.244 & 1.6781 \\
At 12 $\mathrm{h}$ after CPB & $64.34 \pm 15.02$ & $85.48 \pm 22.47^{\mathrm{a}, \mathrm{b}}$ & $\mathrm{P}<0.05$ & 5.468 & $\mathrm{P}<0.05$ & 4.6147 \\
At 24 $\mathrm{h}$ after CPB & $64.17 \pm 13.57$ & $118.29 \pm 34.63^{\mathrm{a}, \mathrm{b}}$ & $\mathrm{P}<0.05$ & 11.324 & $\mathrm{P}<0.05$ & 10.9608 \\
At 48 $\mathrm{h}$ after CPB & $61.54 \pm 10.44$ & $124.61 \pm 38.61^{\mathrm{a}, \mathrm{b}}$ & $\mathrm{P}<0.05$ & 13.173 & $\mathrm{P}<0.05$ & 13.6250 \\
\hline
\end{tabular}

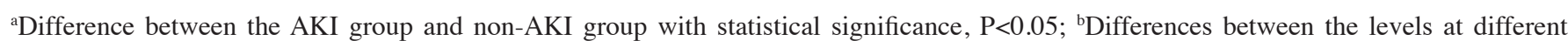
time-points and the level before surgery in the AKI group with statistical significance, $\mathrm{P}<0.05$. Scr, serum creatinine; AKI, acute kidney injury; $\mathrm{CPB}$, cardiopulmonary bypass.

Table II. The levels of uIL-18 at different time-points in non-AKI group and AKI group ( $\mu \mathrm{g} / 1$, mean $\pm \mathrm{SD})$.

\begin{tabular}{lccccrr}
\hline Time-point & Non-AKI group & AKI group & P-value & t-test & P-value & F-value \\
\hline Before CPB & $0.91 \pm 0.46$ & $0.98 \pm 0.32$ & 0.4123 & 0.823 & & \\
At 2 h after CPB & $0.95 \pm 0.51$ & $4.89 \pm 0.96^{\mathrm{a}, \mathrm{b}}$ & $\mathrm{P}<0.05$ & 18.508 & $\mathrm{P}<0.05$ & 9.0000 \\
At 4 h after CPB & $1.13 \pm 0.79$ & $4.46 \pm 1.56^{\mathrm{a}, \mathrm{b}}$ & $\mathrm{P}<0.05$ & 13.849 & $\mathrm{P}<0.05$ & 23.7656 \\
At 6 h after CPB & $1.05 \pm 0.74$ & $4.01 \pm 1.21^{\mathrm{a}, \mathrm{b}}$ & $\mathrm{P}<0.05$ & 14.330 & $\mathrm{P}<0.05$ & 14.2979 \\
At 8 h after CPB & $1.19 \pm 0.67$ & $3.79 \pm 1.42^{\mathrm{a}, \mathrm{b}}$ & $\mathrm{P}<0.05$ & 12.286 & $\mathrm{P}<0.05$ & 19.6914 \\
At 12 h after CPB & $1.22 \pm 0.74$ & $3.73 \pm 1.61^{\mathrm{a}, \mathrm{b}}$ & $\mathrm{P}<0.05$ & 10.586 & $\mathrm{P}<0.05$ & 25.3135 \\
\hline
\end{tabular}

${ }^{\mathrm{a} D i f f e r e n c e}$ between the AKI group and non-AKI group with statistical significance, $\mathrm{P}<0.05$; ${ }^{\mathrm{b}}$ Differences between the levels at different timepoints and the level before surgery in the AKI group with statistical significance, $\mathrm{P}<0.05$. uIL-18, urinary interleukin- 18 ; AKI, acute kidney injury; $\mathrm{CPB}$, cardiopulmonary bypass.

Ethics Committee of Zhengzhou No. 7 People's Hospital, and all patients or their family signed the informed consent.

Methods. We collected the urine samples before and at 2,4,6,8 and $12 \mathrm{~h}$ after CPB and the blood samples before and at 12, 24, 48 and $72 \mathrm{~h}$ after CPB for centrifugation, and the supernatant was collected for detecting the levels of uIL-18 and UNGAL in urine samples and the levels of Scr in blood samples, in which the Scr level was measured with an Automatic Biochemistry Analyzer, while uNGAL and uIL-18 levels in urine by enzyme-linked immunosorbent assay (ELISA). The ELISA kit was purchased from R\&D Systems (Minneapolis, MN, USA).

Statistical analysis. In this study, statistical analysis on experiment data was performed by SPSS 19.0 software (NDtimes, Beijing, China). Data in normal distribution are presented as mean \pm standard deviation (mean $\pm \mathrm{SD}$ ). For comparisons of data among groups and between different time-points, t-test and analysis of variance were carried out. Receiver operating characteristic (ROC) curve and area under curve (AUC) were used to evaluate the sensitivity and specificity of uIL-18 and uNGAL on AKI. $\mathrm{P}<0.05$ suggested that the difference had statistical significance.

\section{Results}

Incidence rate of AKI. Among 103 patients who received the $\mathrm{CPB}$, there were 22 patients $(21.4 \%)$ with AKI, while remaining
81 patients had no AKI, indicating that the incidence rate of AKI was $21.4 \%$. Among those with AKI, there were 10 females and 12 males with an average age of $59 \pm 10.2$ years, while in those with no AKI, there were 39 females and 42 males with an average age of $58 \pm 7.9$ years. We found no statistically significant difference in comparisons of gender ratio and age between the two groups.

From $12 \mathrm{~h}$ after CPB, the level of Scr in the AKI group was significantly elevated, and this increasing trend lasted till $72 \mathrm{~h}$; comparisons with the levels before CPB and in non-AKI group showed that the differences were statistically significant $(\mathrm{P}<0.05)$. In the non-AKI group, there was no significant difference in comparison of Scr level before and after CPB, and the difference had no statistical significance (Table I).

Variations in level of uIL-18. In AKI group, uIL-18 attained the peak level at $2 \mathrm{~h}$ after CPB, and the high level lasted for $10 \mathrm{~h}$, and comparisons with the levels before $\mathrm{CPB}$ and in non-AKI group showed that the differences had statistical significance $(\mathrm{P}<0.05)$; the level of uIL-18 after CPB in the non-AKI group was slightly higher than that before $\mathrm{CPB}$, but the difference had no statistical significance $(\mathrm{P}>0.05)$ (Table II). To assess the diagnostic value of uIL-18 after CPB, the level of uIL-18 at a certain time-point was adopted for statistical analysis and preparation of ROC curve. Since uIL-18 attained the peak level at $2 \mathrm{~h}$ after $\mathrm{CPB}$, we selected this time-point to perform further study. At $2 \mathrm{~h}$ after CPB, the AUC of ROC curve of uIL-18 was 90.48, and when the critical value was set as 
Table III. Distribution of uIL-18 concentrations in patients at $2 \mathrm{~h}$ after CPB.

\begin{tabular}{lrrrrr}
\hline & \multicolumn{2}{c}{ AKI } & & \multicolumn{2}{c}{ non-AKI } \\
\cline { 2 - 3 } \cline { 5 - 6 } uIL-18 $(\mu \mathrm{g} / \mathrm{l})$ & $\mathrm{n}$ & Total & & $\mathrm{n}$ & Total \\
\hline$>0.1$ & 0 & 22 & & 81 \\
$>0.6$ & 1 & 22 & & 37 & 73 \\
$>1.1$ & 1 & 21 & 25 & 36 \\
$>1.6$ & 2 & 20 & & 4 & 11 \\
$>2.1$ & 1 & 18 & & 7 \\
$>2.6$ & 1 & 17 & & 5 \\
$>3.1$ & 0 & 16 & & 3 \\
$>3.6$ & 2 & 16 & & 1 \\
$>4.1$ & 5 & 14 & & 0 & 0 \\
$>4.6$ & 5 & 9 & & 0 & 0 \\
$>5.1$ & 4 & 4 & & 0 & 0 \\
Total & 22 & & 81 & \\
\hline
\end{tabular}

uIL-18, urinary interleukin-18; AKI, acute kidney injury; CPB, cardiopulmonary bypass.

$1.6 \mu \mathrm{g} / \mathrm{l}$, the sensitivity and specificity was 90.91 and $91.36 \%$, where the uIL-18 level in most of the patients in the AKI group was $>1.6 \mu \mathrm{g} / \mathrm{l}$, but there were only 11 patients $(11 / 81)$ in the non-AKI group with a level $>1.6 \mu \mathrm{g} / 1$ (Table III and Fig. 1).

Variations in level of $u N G A L$. In the AKI group, a significant elevation in uNGAL level at $2 \mathrm{~h}$ after CPB followed by a rapid decrease was seen, and difference between the level at $2 \mathrm{~h}$ after $\mathrm{CPB}$ and the level before $\mathrm{CPB}$ as well as that in the non-AKI group had statistical significance $(\mathrm{P}<0.05)$. However, at $12 \mathrm{~h}$ after $\mathrm{CPB}$, these differences had no statistical significance $(\mathrm{P}>0.05)$, and in the non-AKI group, there was no statistically significant difference in comparison to the UNGAL level before and after CPB (Table IV). To assess the diagnostic value of uNGAL level after CPB, the level of uNGAL at a certain time-point was adopted for statistical analysis and preparation of ROC curve. Since a significant elevation in UNGAL was attained at $2 \mathrm{~h}$ after CPB, which was not significantly different from the peak level attained at $4 \mathrm{~h}$ after $\mathrm{CPB}$, we selected this time-point to perform further study. At $2 \mathrm{~h}$ after CPB, the AUC of ROC curve of uNGAL was 83.25 , and when the critical value was set as $100 \mu \mathrm{g} / 1$, the sensitivity and specificity, respectively, was 90.91 and $93.83 \%$, where the uNGAL level in most of the patients (20/22) in the AKI group was $>1.6 \mu \mathrm{g} / 1$, but there were only 7 patients (7/81) in the non-AKI group with a level $>100 \mu \mathrm{g} / 1$ (Table V and Fig. 2).

\section{Discussion}

Various factors affect the renal functions in surgeries, particularly the $\mathrm{CPB}$, which can induce severe complications, such as acute renal failure that has poor prognosis, and frequently leads to continuous increased incidence rates and mortality without immediate intervention and treatment $(10,11)$. Recently, AKI was put forward by the international nephrology

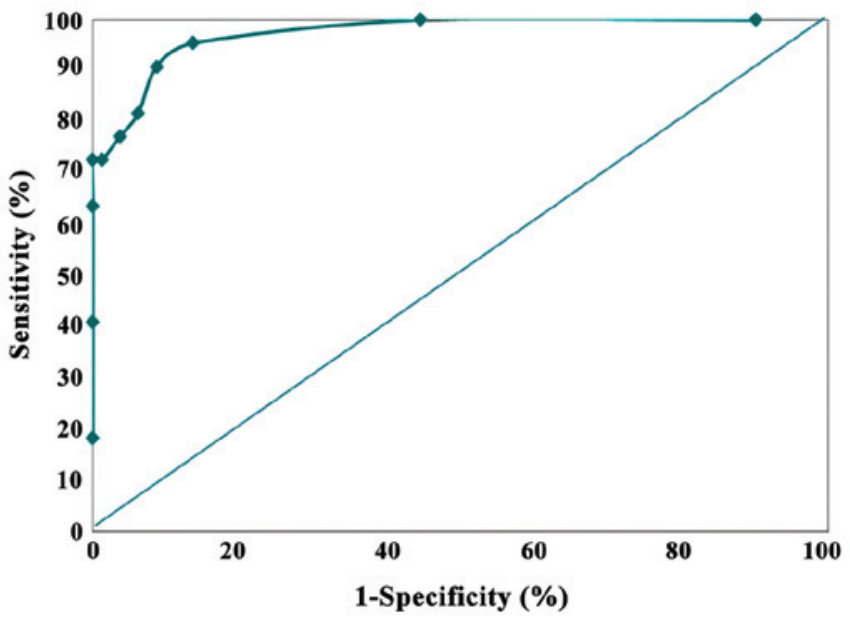

Figure 1. Receiver operating characteristic (ROC) curve of urinary interleukin-18 (uIL-18) in patients at $2 \mathrm{~h}$ after cardiopulmonary bypass (CPB). The area under curve (AUC) is 90.48 , and when the critical value is $1.6 \mu \mathrm{g} / 1$, the sensitivity and specificity is 90.91 and $91.36 \%$, respectively.

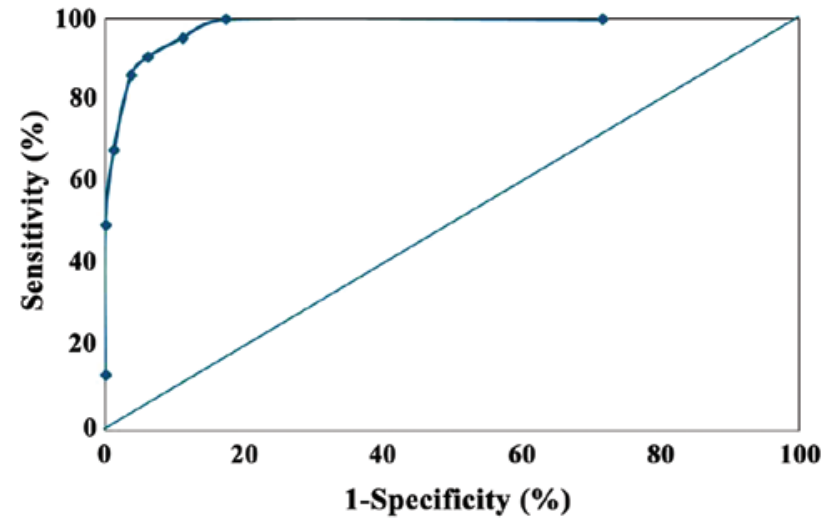

Figure 2. Receiver operating characteristic (ROC) curve of urinary neutrophil gelatinase-associated lipocalin (uNGAL) in patients at $2 \mathrm{~h}$ after cardiopulmonary bypass (CPB). The area under curve (AUC) is 83.25 , and when the critical value is $100 \mu \mathrm{g} / 1$, the sensitivity and specificity is 90.91 and $93.83 \%$, respectively.

communication for accurate prediction and early diagnosis and treatment; the attack of AKI without any effective intervention and treatment will aggravate the kidney impairment, or even lead to death $(12,13)$. Thus, early diagnosis of AKI is of great significance for prognosis of patients. So far, Scr has been used as a conventional indicator for detection of renal function, but the obvious increase in content of Scr is usually identified at $12 \mathrm{~h}$ after surgery; thus, Scr cannot timely reflect the impairment of kidney (14). Hence, it is prioritized to search for biological indicators for early diagnosis of AKI in clinical practice.

Ischemic reperfusion in kidney is a key factor inducing the attack of AKI after CPB for it can initiate the expression of IL-18, thereby resulting in the inflammatory responses in kidney and AKI (15). An ischemic AKI experiment has proved that damage to kidney tubules will give rise to massive release of IL-18 into the urine; thus, we can detect the content of IL-18 using the urine sample (16); a clinical study confirmed that in patients with ischemia or late-onset transplantation rejection after kidney transplantation, a significant elevation is also 
Table IV. The levels of uNGAL at different time-points in non-AKI group and AKI group ( $\mu \mathrm{g} / 1, \mathrm{mean} \pm \mathrm{SD})$.

\begin{tabular}{lcccrrr}
\hline Time-point & Non-AKI group & AKI group & P-value & t-test & P-value & F-value \\
\hline Before CPB & $34.91 \pm 9.46$ & $36.74 \pm 8.02$ & 0.4089 & 0.829 & & \\
At 2 h after CPB & $36.91 \pm 12.55$ & $425.41 \pm 18.96^{\mathrm{a}, \mathrm{b}}$ & $\mathrm{P}<0.05$ & 114.408 & $\mathrm{P}<0.05$ & 5.5889 \\
At 4 h after CPB & $35.13 \pm 17.42$ & $527.47 \pm 17.54^{\mathrm{a}, \mathrm{b}}$ & $\mathrm{P}<0.05$ & 117.389 & $\mathrm{P}<0.05$ & 4.7831 \\
At 6 h after CPB & $32.25 \pm 11.84$ & $358.01 \pm 15.9^{\mathrm{a}, \mathrm{b}}$ & $\mathrm{P}<0.05$ & 105.935 & $\mathrm{P}<0.05$ & 3.9305 \\
At h after CPB & $29.48 \pm 8.67$ & $105.79 \pm 21.42^{\mathrm{a}, \mathrm{b}}$ & $\mathrm{P}<0.05$ & 25.500 & $\mathrm{P}<0.05$ & 7.1333 \\
At 12 h after CPB & $30.22 \pm 9.74$ & $35.03 \pm 12.17$ & 0.0547 & 1.944 & 0.063 & 2.3027 \\
\hline
\end{tabular}

${ }^{\mathrm{a} D i f f e r e n c e ~ b e t w e e n ~ t h e ~ A K I ~ g r o u p ~ a n d ~ n o n-A K I ~ g r o u p ~ w i t h ~ s t a t i s t i c a l ~ s i g n i f i c a n c e, ~} \mathrm{P}<0.05$; ${ }^{\mathrm{b}}$ Differences between the levels at different timepoints and the level before surgery in the AKI group with statistical significance, $\mathrm{P}<0.05$. AKI, acute kidney injury; $\mathrm{CPB}$, cardiopulmonary bypass; uNGAL, urinary neutrophil gelatinase-associated lipocalin.

Table V. Distribution of uNGAL concentrations in patients at $2 \mathrm{~h}$ after $\mathrm{CPB}$.

\begin{tabular}{lrrrrr}
\hline & \multicolumn{2}{c}{ AKI } & & \multicolumn{2}{c}{ non-AKI } \\
\cline { 2 - 3 } \cline { 5 - 6 } uNGAL $(\mu \mathrm{g} / \mathrm{l})$ & $\mathrm{n}$ & Total & & $\mathrm{n}$ & Total \\
\hline$>10$ & 0 & 22 & 24 & 81 \\
$>30$ & 1 & 22 & 44 & 57 \\
$>60$ & 2 & 21 & 5 & 13 \\
$>100$ & 1 & 20 & & 4 & 8 \\
$>200$ & 3 & 19 & & 4 \\
$>300$ & 4 & 15 & 2 & 2 \\
$>400$ & 8 & 11 & & 0 \\
$>500$ & 3 & 3 & 0 & 0
\end{tabular}

AKI, acute kidney injury; uNGAL, urinary neutrophil gelatinaseassociated lipocalin; CPB, cardiopulmonary bypass.

identified in the content of uIL-18 $(17,18)$. In addition, the AKI in patients will facilitate the generation of NGAL that can protect the renal tissues (19). Study has shown that the expression of NGAL is quite low in normal renal tissues, but under the kidney impairment, NGAL will be rapidly secreted by the epithelial cells of tubules to protect the integrity of tubules, which is usually accompanied by a quick increase in concentration of NGAL in urine $(6,20)$. Thus, uIL-18 or uNGAL may be a candidate for indicators in detection of AKI, and they have become a research hotspot.

In this study, the results showed that among 103 patients undergoing $\mathrm{CPB}$, there were 22 patients with $\mathrm{AKI}$ after $\mathrm{CPB}$, which coincide with a previous study (16). Compared with the levels before surgery and those in non-AKI group, a significant elevation was identified at $12 \mathrm{~h}$ after $\mathrm{CPB}$ in patients of the AKI group, lasting till $72 \mathrm{~h}$ after $\mathrm{CPB}$, and the differences had statistical significance $(\mathrm{P}<0.05)$, which is also consistent with previous studies, suggesting that this period is suitable for diagnosis of AKI using Scr (17). Among the AKI patients, maximal level of uIL-18 was attained at $2 \mathrm{~h}$ after CPB, and the high level lasted till $12 \mathrm{~h}$; comparisons between the uIL-18 level at this time-point and the level before CPB as well as that in the non-AKI group showed that the differences had statis- tical significance $(\mathrm{P}<0.05)$. However, peak level of $\mathrm{uNGAL}$ was identified at $4 \mathrm{~h}$ after $\mathrm{CPB}$, which could only be sustained for $8 \mathrm{~h}$ after $\mathrm{CPB}$; the result is also coincident with previous reports $(6,19)$. Shortly after $C P B$, a slight increase was seen in patients of the non-AKI group, which may be caused by the release of inflammatory factors (15). To provide better clinical service, we further confirmed the critical values of uIL-18 and UNGAL at $2 \mathrm{~h}$ after CPB with promising sensitivity and specificity, and the results showed that when the critical values of uIL-18 and UNGAL were 1.6 and $100 \mu \mathrm{g} / 1$, respectively, these indicators showed good sensitivity and specificity; besides, the AUC of ROC was, respectively, 90.48 and 83.25 , suggesting that the results are reliable. The result of this study also conforms to the reports of studies by other groups $(18,20)$.

In conclusion, although rapid increases in uIL-18 and uNGAL levels were found in a short time in patients with AKI after CPB, the emergence of peak value in UIL-18 level after CPB is earlier than the UNGAL, and the high level of uIL-18 can be sustained for a long time. Thus, uIL-18 has a better clinical value for early diagnosis and intervention of the development and progression of AKI.

\section{References}

1. Reddy SL, Grayson AD, Griffiths EM, Pullan DM and Rashid A: Logistic risk model for prolonged ventilation after adult cardiac surgery. Ann Thorac Surg 84: 528-536, 2007.

2. Bellomo R, Kellum JA and Ronco C: Defining acute renal failure: Physiological principles. Intensive Care Med 30: 33-37, 2004

3. Doddakula K, Al-Sarraf N, Gately K, Hughes A, Tolan M, Young V and McGovern E: Predictors of acute renal failure requiring renal replacement therapy post cardiac surgery in patients with preoperatively normal renal function. Interact Cardiovasc Thorac Surg 6: 314-318, 2007.

4. Song S, Meyer M, Türk TR, Wilde B, Feldkamp T, Assert R, Wu K, Kribben A and Witzke O: Serum cystatin C in mouse models: A reliable and precise marker for renal function and superior to serum creatinine. Nephrol Dial Transplant 24: 1157-1161, 2009.

5. Jin Y, Shao X, Sun B, Miao C, Li Z and Shi Y: Urinary kidney injury molecule 1 as an early diagnostic biomarker of obstructive acute kidney injury and development of a rapid detection method. Mol Med Rep 15: 1229-1235, 2017.

6. Devarajan P: Neutrophil gelatinase-associated lipocalin (NGAL): A new marker of kidney disease. Scand J Clin Lab Invest (Suppl) 241: 89-94, 2008.

7. Mishra J, Dent C, Tarabishi R, Mitsnefes MM, Ma Q, Kelly C, Ruff SM, Zahedi K, Shao M, Bean J, et al: Neutrophil gelatinaseassociated lipocalin (NGAL) as a biomarker for acute renal injury after cardiac surgery. Lancet 365: 1231-1238, 2005. 
8. Nguyen MT and Devarajan P: Biomarkers for the early detection of acute kidney injury. Pediatr Nephrol 23: 2151-2157, 2008.

9. Goldstein SL: Pediatric acute kidney injury: It's time for real progress. Pediatr Nephrol 21: 891-895, 2006.

10. Nunag M, Brogan M and Garrick R: Mitigating contrast-induced acute kidney injury associated with cardiac catheterization. Cardiol Rev 17: 263-269, 2009.

11. Karkouti K, Wijeysundera DN, Yau TM, Callum JL, Cheng DC, Crowther M, Dupuis JY, Fremes SE, Kent B, Laflamme C, et al: Acute kidney injury after cardiac surgery: Focus on modifiable risk factors. Circulation 119: 495-502, 2009.

12. Wu Y, Wang L, Meng L, Cao GK and Zhang Y: MIP- $1 \alpha$ and $\mathrm{NF}-\kappa \mathrm{B}$ as indicators of acute kidney injury secondary to acute lung injury in mechanically ventilated patients. Eur Rev Med Pharmacol Sci 20: 3830-3834, 2016.

13. Nissenson AR: Acute renal failure: Definition and pathogenesis. Kidney Int (Suppl) 66: S7-S10, 1998

14. Pirgakis KM, Makris K, Dalainas I, Lazaris AM, Maltezos CK and Liapis CD: Urinary cystatin C as an early biomarker of acute kidney injury after open and endovascular abdominal aortic aneurysm repair. Ann Vasc Surg 28: 1649-1658, 2014.

15. Parikh CR, Jani A, Melnikov VY, Faubel S and Edelstein CL: Urinary interleukin-18 is a marker of human acute tubular necrosis. Am J Kidney Dis 43: 405-414, 2004.
16. Melnikov VY, Faubel S, Siegmund B, Lucia MS, Ljubanovic D and Edelstein CL: Neutrophil-independent mechanisms of caspase-1- and IL-18-mediated ischemic acute tubular necrosis in mice. J Clin Invest 110: 1083-1091, 2002.

17. Parikh CR, Mishra J, Thiessen-Philbrook H, Dursun B, Ma Q, Kelly C, Dent C, Devarajan P and Edelstein CL: Urinary IL-18 is an early predictive biomarker of acute kidney injury after cardiac surgery. Kidney Int 70: 199-203, 2006.

18. Han WK, Wagener G, Zhu Y, Wang S and Lee HT: Urinary biomarkers in the early detection of acute kidney injury after cardiac surgery. Clin J Am Soc Nephrol 4: 873-882, 2009.

19. Bolignano D, Lacquaniti A, Coppolino G, Donato V, Campo S, Fazio MR, Nicocia G and Buemi M: Neutrophil gelatinaseassociated lipocalin (NGAL) and progression of chronic kidney disease. Clin J Am Soc Nephrol 4: 337-344, 2009.

20. Shemin D and Dworkin LD: Neutrophil gelatinase-associated lipocalin (NGAL) as a biomarker for early acute kidney injury. Crit Care Clin 27: 379-389, 2011. 